\title{
Relações autoritárias em espaços feministas de universidades brasileiras
}

\author{
Authoritarian relations in feminist spaces at Brazilian universities \\ Relaciones autoritarias en espacios feministas en las universidades brasileñas
}

Sonia Jay Wright ${ }^{1}$

Igor Leonardo de Santana Torres ${ }^{2}$

\begin{abstract}
“Todas as situações de assédio moral, de silenciamento, que eu sofri, partiram de mulheres." (Interlocutora 8)
\end{abstract}

\section{Resumo}

WRIGHT, Sonia Jay; TORRES, Igor Leonardo de Santana. Relações autoritárias em espaços feministas de universidades brasileiras. Rev. CઐTrópico, v. 44, n.2, p. 227-253, 2020. DOI: https:// doi.org/10.33148/cetropicov44n2(2020)art8

É o espaço das universidades brasileiras, mais especificamente, dos núcleos e grupos de estudo sobre mulheres, relações de gênero e feminismos, onde o tema das relações de poder autoritárias em espaços teoricamente comprometidos com a democratização das relações sociais, compostos principalmente por mulheres feministas acadêmicas é o contexto desta pesquisa. Os objetivos desse trabalho são contribuir para o conhecimento das relações de poder no interior de instâncias feministas em universidades brasileiras e para o aprofundamento da democracia em espaços feministas acadêmicos. Busca-se também trazer à tona as experiências de pessoas que vivenciaram situações não democráticas em espaços feministas de universidades, bem como evidenciar a existência de práticas autoritárias nesses espaços. Objetiva-se ainda mostrar uma concepção de democracia feminista para servir de parâmetro para comparação com as práticas opressoras impostas em instâncias acadêmicas feministas e apontar caminhos para o exercício de poder de forma mais igualitária nessas instâncias.

Palavras-chave: feminismo. Autoritarismo. Democracia. Academia. Grupos feministas.

1 Pós-doutora pela Fundação Joaquim Nabuco, professora do Bacharelado de Estudos em Gênero e Diversidade (BEGD), da Universidade Federal da Bahia, e co-líder do Grupo de Pesquisa e Ação em Gênero, Direito e Políticas para a Igualdade - Jusfemina. wri2sonia@hotmail.com. Orcid: https://orcid. org/0000-0002-4143-1996

2 Pesquisador Assistente, estudante do BEGD e integrante do GIRA-Grupo de Estudos Feministas em Política e Educação. E-mail: torres.igorsantana@gmail.com. ORCID: https://orcid.org/0000-0001-74553212 ?lang $=$ pt. 


\section{Abstract}

WRIGHT, Sonia Jay; TORRES, Igor Leonardo de Santana. Authoritarian relations in feminist spaces at Brazilian universities. Rev. C\&Trópico, v. 44, n.2, p. 227-253, 2020. DOI: https://doi. org/10.33148/cetropicov44n2(2020)art8

The context of this research are Brazilian universities, more specifically, the groups that study women, gender relations and feminism. The focus is authoritarian power relations in spaces theoretically committed to the democratization of social relations as academic feminists. The objectives of this paper are to contribute to the knowledge of power relations in feminist spaces in Brazilian universities and to deepen democracy in academic feminist spaces. This article also brings the experience of teachers and researchers who went through non democratic situations in feminist spaces of universities, as well authoritarian practices in these spaces. A last objective is to show a concept of feminist democracy to serve as a parameter to compare with oppressive practices in feminist academic spaces and point out ways to exercise power more equally in these spaces.

Keywords: Feminism. Authoritarianism. Democracy. Universities. Feminist groups.

\section{Resumen}

WRIGHT, Sonia Jay; TORRES, Igor Leonardo de Santana. Relaciones autoritarias en espacios feministas en las universidades brasileñas. Rev. C\&Trópico, v. 44, n.2, p. 227-253, 2020. DOI: https:// doi.org/10.33148/cetropicov44n2(2020)art8

Es el espacio de las universidades brasileñas, más específicamente los núcleos y grupos de estudio sobre mujeres, relaciones de género y feminismos, donde se pauta el tema de las relaciones de poder autoritarias en espacios teóricamente comprometidos con la democratización de las relaciones sociales, compuestos principalmente por mujeres feministas académicas. Los objetivos de este trabajo son contribuir para el conocimiento de las relaciones de poder en el interior de instancias feministas en universidades brasileñas y para el perfeccionamiento de la democracia en espacios feministas académicos. Se busca incluso destacar las experiencias de personas que vivenciaron situaciones no democráticas en espacios feministas de universidades, así como evidenciar la existencia de prácticas autoritarias en esos espacios. Se tiene como objetivo aun mostrar una concepción de democracia feminista para servir de parámetro para comparación con las prácticas opresoras impuestas en instancias académicas feministas y apuntar caminos para el ejercicio de poder de forma más igualitaria en esas instancias.

Palabras clave: Feminismo. Autoritarismo. Democracia. Academia. Grupos. 


\section{Introdução}

Adorno (1950), associado à Escola de Frankfurt de teoria social e política, pesquisou empiricamente, nos Estados Unidos, a personalidade autoritária ${ }^{3}$ e a sua faceta de discriminação social, que se configuram em tendências políticas e sociais em processos históricos que ameaçam a democracia. Adorno também, neste mesmo livro, chama a atenção para o fato de que os sujeitos autoritários tendem a apresentar um discurso contraditório: reconhecem muitas vezes a democracia como algo próximo do ideal do que deveria ser a sociedade (TORRES, 2020), mas a utilização da força ou da violência pressupõe autoritarismo (BUENO, 2013).

$\mathrm{O}$ referido estudo abriu caminhos para investigações que enfrentam o autoritarismo em diversos espaços da sociedade, como a presente pesquisa. Escolhemos o espaço das universidades brasileiras, mais especificamente os núcleos e grupos de estudos sobre mulheres, relações de gênero e feminismos, para pautar o tema das relações de poder autoritárias em espaços teoricamente comprometidos com a democratização das relações sociais, compostos principalmente por mulheres feministas acadêmicas.

Muito se tem falado sobre a contribuição dos feminismos à democracia ( SILVA, 2011, 2018a, 2018b, 2019; BIROLI, 2013; WRIGHT, 2016; PEDRO; ZANDONÁ, 2019; GONÇALVES; ROCHA, 2019); a relação dos movimentos sociais - entre eles os feministas e de mulheres - e a academia (BONETTI, 2009; ALVAREZ, 2003; GROSSI et al., 2013). Desde a década de 1980, a teoria decolonial introduziu a crítica às acadêmicas feministas do Norte em relação a nós do Sul (MOHANTY, 1988). Há também escritos sobre a produção acadêmica sobre os movimentos feministas e de mulheres (BANDEIRA; OLIVEIRA, 1990) e, ainda, trabalhos sobre os núcleos e grupos de estudos sobre a mulher e relações de gênero na academia (COSTA; SARDENBERG, 2014). No entanto, as relações de poder no interior desses núcleos e grupos ainda não foram abordadas. Este trabalho busca suprir, entre outros objetivos, essa lacuna. Nesse sentido, e ainda de modo a dirimir algumas possíveis dúvidas, reafirmamos que este trabalho não pretende impor uma "verdade", tampouco pretendemos lançar generalizações, mas evidenciamos falas que revelam relações autoritárias e sofrimentos de assédio em espaços feministas universitários, ou seja, um ponto-de-vista, como já mencionado, geralmente não divulgado ou refletido de maneira coletiva.

Outro ponto que deve ser colocado aqui para a pessoa leitora: debruçamo-nos aqui sobre os relatos de 8 pessoas que exerceram ou exercem atividades em núcleos e grupos feministas universitários e sofreram experiências autoritárias e assédio moral decorrente do autoritarismo presente nesses espaços. Propomo-nos a escutar as narrativas dessas pessoas e analisar a partir da perspectiva feminista essas relações de poder. Não estava entre nossos objetivos escutar as posições de quem teria sido colocada pelas nossas Interlocutoras na posição gerente de discursos e práticas

\footnotetext{
A ideia de personalidade autoritária aqui não estabelece um perfil único da pessoa autoritária. Reconhecemos que o autoritarismo pode se expressar intensidades e níveis variados, podendo ser materializado através de ações mais diretas, como também mais brandas.
} 
autoritárias. Dessa forma, não nos coube fazer uma análise apresentando as diversas posições das participantes. Ademais, a caracterização de algumas situações de assédio moral não resume as experiências aqui expostas como tão somente de assédio. Como verão mais adiante, o assédio vai aparecer como um produto de relações autoritárias e difere-se da ideia de conflito.

Os objetivos deste artigo são contribuir para o conhecimento das relações de poder no interior de instâncias feministas em universidades brasileiras e para o aprofundamento da democracia em espaços feministas acadêmicos. Buscamos também trazer à tona as experiências de pessoas que vivenciaram situações não democráticas em espaços feministas de universidades, bem como evidenciar a existência de práticas autoritárias nesses espaços. Ao fim, procuramos, ainda, mostrar uma concepção de democracia feminista para servir de parâmetro para comparação com as práticas opressoras impostas em instâncias acadêmicas feministas e apontar caminhos para o exercício de poder de forma mais igualitária.

\section{Pressupostos teóricos}

Questionar o modelo democrático atual tem sido uma das inclinações teóricas mais profícuas da teoria feminista, facultando um campo de conhecimento e crítica denominado de Teorias Feministas da Democracia. Não sem embates, esse lugar de discussão teórica, que reúne autoras que pensam as desigualdades entre homens e mulheres nos sistemas democráticos, também se constitui em um espaço de tensões e contrastes epistemológicos, onde há "guerras paradigmáticas" (SANCHEZ, 2017, p. 01), ou seja, as disputas em torno do modelo democrático mais coerente e que melhor contribua para o movimento político de luta contra as desigualdades e, por que não, para democratização da participação. e representação.

Essas teorias são úteis para pensarmos as relações de poder em estratos mais macros, mas igualmente micros. No escopo do presente trabalho, elas servirão de suporte para analisar as relações falsamente democráticas e efetivamente autoritárias que informam as práticas individuais e coletivas nos espaços feministas acadêmicos. Propomos o exercício de pensamento posto por Sandra Harding (2007, p. 165): “como valores e interesses antidemocráticos bloqueiam o crescimento do conhecimento, uma vez que calam as mais vigorosas perspectivas críticas sobre modos de pensar antidemocráticos e outros modos dominantes". Quais os limites entre a democracia liberal e socialista e o autoritarismo? Onde o conflito se encaixa nos modelos democráticos que podemos entrever nesses espaços? Qual a contribuição do conflito na construção do pluralismo democrático e como ele pode ser útil para a práxis feminista? A práxis feminista já não devia pressupor o modelo agonístico ao antagônico? (MOUFFE, 2005).

Quando autoras feministas, entre as quais nós nos incluímos ${ }^{4}$, falam em radicalização do Feminismo, fazem referência à radicalização do conflito, apontando

\footnotetext{
Cf. WRIGHT, 2016; TORRES; FERNANDES, 2018.
} 
que o investimento nas contradições, nas críticas e nos embates são a forma pela qual podemos otimizar nossa ação. Explorar e viver os conflitos internos e externos são o caminho para a radicalidade, pois assim podemos produzir práticas acessíveis a um conjunto de sujeitos/as reunidos/as em torno de pautas concretamente distintas. Em caminho contrário. Aquele da não radicalidade (MOUFFE, 2005).

Maria Betânia Ávila (2007, p. 03), ao tempo em que questiona a Democracia nas instituições políticas e no Estado, aponta para a necessidade de revisão dos pressupostos feministas informando que a democracia "requer [...] uma capacidade crítica para combater, em nós mesmas, as formas de agir, herdadas da tradição desse sistema e das tradições políticas autoritárias". Ela faz questionamentos que podemos direcionar ao objeto de estudo deste trabalho: os núcleos feministas nas universidades públicas brasileiras:

Quais são as formas de democracia política que forjamos, teorizamos, praticamos, defendemos e alteramos? É a representativa, a participativa, a democracia direta? Como podemos democratizar o sistema de poder político? Como o feminismo enfrenta, de fato, o sistema de poder político, produz crítica e confronto? Como se apresenta, agora, para o movimento feminista, a questão do poder? (ÁVILA, 2007, p. 03).

A perspectiva teórica dessa autora imbui-se da noção de "pluralismo agonístico", de Chantal Mouffe, para quem o conflito está no centro dos debates sobre Democracia e o que lhe importa não é a abstração do poder, mas a exata compreensão da inerradicabilidade do conflito (relações de poder) e a capacidade de saber conduzir essas relações de forma mais democrática. Nesse sentido, seria necessário radicalizar e admitir conflitos, repensar as relações hierárquicas dentro do feminismo, e não representar um modelo preexistente. A democracia aqui é vista não no sentido liberal (MIYARES, 2003), mas com seu significado radical, de democracia na vida, onde as relações entre as pessoas também são políticas e apresentam conflitos.

Assim, partimos também de uma Antropologia Feminista (AF) (BONETTI, 2009) como aporte teórico-metodológico útil para pesquisas de caráter feminista com vistas ao desvelar das relações de poder. Segundo a autora, a AF constitui-se na sua íntima relação com a etnografia e a reflexão sobre o poder e a agência. Essa abordagem toma o poder "como parte constituinte de todos os níveis da produção de conhecimento e se faz crucial dar visibilidade para as suas implicações." (BONETTI, 2009, p. 109).

De uma concepção foucaultiana de poder (FOUCAULT, 1985; 2014), consideramos que nenhum espaço está livre das operações de poder, o conhecimento, ele mesmo, é produto de processos discursivos, disputas, críticas e revisões. Nesse sentido, a AF junto às teorias democráticas feministas contribui para reflexão sobre as relações de poder escamoteadas e o autoritarismo pervasivo de espaços feministas que vai contra os princípios feministas. 
Na práxis dos núcleos e grupos de estudo sobre feminismos, relações de gênero e mulheres, como se configura a democracia feminista? A seguir, apresentamos dados sobre esses núcleos.

\section{Metodologia}

Um aspecto a ressaltar na metodologia é a realização de uma autoetnografia no seio deste trabalho. Segundo Versiani (2005), a autobiografia, relacional e não linear, caracteriza-se por sua ênfase do self, uma construção e processo que visibiliza a subjetividade de forma dialógica e a memória pessoal e coletiva, elemento indispensável na produção do conhecimento, um conhecimento situado, principalmente em se tratando de pesquisadoras-militantes, que exercem e defendem a ideia de uma ciência engajada. $\mathrm{O}$ resultado é uma singularidade, fruto da trajetória pessoal historicizada e móvel. Nesse ponto, vale lembrar as considerações de Donna Haraway (2009) sobre saberes localizados, o questionamento da objetividade como axioma das ciências, e como ela só pode ser exercida de forma crítica se levado em consideração os fundamentos subjetivos que permeiam a produção do saber.

Quanto às entrevistas, elas são importantes na coleta de dados e envolvem crenças, valores significados, atitudes, motivações e opiniões. A conversa, interação e o relembrar da vida das pessoas entrevistadas, o retomar a vivência, de forma retrospectiva, de seus grupos e organizações, contribuem para entrevistas em profundidade e abertas, com menor interferência da entrevistadora e maior confiança entre interlocutoras. Uma de suas vantagens é a troca mais afetiva entre interlocutoras, a elasticidade da duração da entrevista, graças à maior proximidade entre entrevistadora e entrevistadas, o falar a mesma língua, o alívio por falar que permite o se fazer ouvir, numa espécie de autoanálise provocada e acompanhada, com silêncios, risos e entonações, bem como a espontaneidade entre ambas, que preservam a informalidade e pontualidade, com a intermediação do gravador.

Por fim, há-se que pontuar que a amostra foi determinada de forma intencional, uma seleção por critério de vivência em núcleo ou grupo de feministas acadêmicas com experiências de falta de democracia interna, dispostas a compartilhar sua trajetória e dores, a familiaridade com o tema pesquisado e a disponibilidade de acesso pela pesquisadora. Algum/as da/os entrevistadas são de mesmos núcleos ou grupos. O anonimato das entrevistadas foi preservado, assim como quaisquer outros elementos que facilitem sua identificação, inclusive aqueles contidos nos excertos utilizados neste artigo.

\section{Perfil das pessoas entrevistadas}

Todas as pessoas entrevistadas são/ou foram docentes ou pesquisadoras/es em Instituições de Ensino Superior (IES), tendo passado parte da formação, experiência de pesquisa ou docência vinculadas a grupos ou núcleos/centros de pesquisas de caráter feminista. Toda/os foram entrevistada/os entre janeiro e março de 2020. 
Nossas interlocutoras são das regiões Nordeste, Sudeste e Sul do país, e viveram experiências em espaços feministas dentro e fora das suas regiões, posto que algumas delas fizeram parte de sua formação - e estão docentes e pesquisadoras em Universidades - em outros Estados. O perfil de gênero das interlocutoras incluiu dois homens que vivenciaram relações autoritárias e também sofreram ou sofrem assédio moral, prática que geralmente encontra-se no regime autoritário, em espaços feministas em universidades ${ }^{5}$. No total, oito pessoas foram entrevistadas, seis brancas, uma negra e uma parda, o que reflete a desigualdade racial da composição atual do quadro docente das universidades ${ }^{6}$.

Quanto à orientação sexual das entrevistadas: duas pessoas são bissexuais, uma homossexual e as outras cinco heterossexuais, o que revela uma certa diversidade sexual. Principalmente a pessoa gay sofreu assédio também por conta de sua sexualidade. Por outro lado, as práticas espirituais das interlocutoras envolvem desde o candomblé e umbanda, a espírita e protestante, além de entrevistadas sem religião ou ateístas, que também podem ser fatores de discriminação. Profissionalmente, o grupo é diverso, envolvendo antropólogas, advogadas, cientistas sociais, filósofas e cientistas políticas, o que mostra a multiplicidade interna do feminismo como componente interdisciplinar. A idade do grupo situa-se entre 35 e 80 anos, perpassando o assédio por diversas gerações.

\section{Histórico dos núcleos e grupos de estudos sobre a mulher, gênero e feminismo}

Ana Alice Costa e Cecília Sardenberg $(2014)^{7}$ sugerem uma compreensão simbiótica entre teoria e prática feminista no que concerne a criação de núcleos feministas posto que tanto o movimento tem servido de inspiração às teorias quanto estas têm contribuído para o fortalecimento do movimento. Apontam que "os núcleos da mulher representam a expressão de um momento ou de uma fase imprescindível na constituição de um novo campo do saber, na qual se processa a construção do seu objeto de estudo." (COSTA; SARDENBERG, 2014, p. 35).

O cerne do questionamento das autoras é, sem dúvidas, o lugar dos núcleos e das feministas acadêmicas na publicização, discussão e transformação de problemáticas que dizem respeito ao acesso e a permanência de mulheres nas universidades e desenvolvimento do campo dos Estudos de Gênero nas instituições públicas de ensino

\footnotetext{
Segundo Karla Adrião e Marion Quadros (2010), homens podem ser parceiros e aliados do feminismo, desde que identificados com valores e princípios dessa corrente teórica e comprometidos com sua prática. No entanto a resistência em integrar homens está expressa na seguinte afirmação: "Sugestão trazer mais homens ali, para gente ter mais participação de outras pessoas e eu fui indicar homens feministas para participar. Foi vetado: 'não, isso aqui é um espaço de poder. Nós não vamos partilhar nosso poder com homem nenhum”'. (Interlocutora 5).

6 Na sua pesquisa realizada na Universidade Federal da Bahia, Ângela de Brito (2017) mostra que, no total de 1252 professores/as de duas entre as seis áreas de conhecimento, 1016 (81\%) são brancos/as e apenas 236 (19\%) são negros/as. Sua pesquisa, embora não conclusiva e geral, já aponta essa desigualdade racial entre docentes das IES do país.

A lista a seguir é datada, portanto, incompleta.
} 
superior. Elas indagam: "será que as mulheres docentes estarão apenas reproduzindo as 'velhas' práticas e representações?” (COSTA; SARDENBERG, 2014, p. 38)

Compreendendo-se a existência de diferenças em termos de exigências políticas e tempo na militância e na ciência, elas observam um distanciamento, antes não visto, entre o movimento e a produção teórica na academia. Nesse sentido, consoante aos seus questionamentos, indagamos ainda: os princípios feministas de horizontalidade e democracia, norteadores da ação política, ainda são lembrados? Como estão organizadas as relações de poder? E como elas fazem face às contradições? Há um trabalho reflexivo sobre elas, como propõem as autoras?

Desde a abertura do campo de estudos sobre a mulher, com a defesa da tese de Heleieth Saffioti, em 1967, e publicação, em 1976, o Brasil viu o fértil desenvolvimento de trabalhos, pesquisas e debates sobre as mulheres, feminismo e, posteriormente, os estudos de gênero. Pesquisadoras começavam a tomar a mulher como sujeito de pesquisa e as questões de suas realidades como problemas de seus trabalhos (SCHUCK, 2018). De acordo com Ana Alice Costa; Cecília Sardenberg (2014), em 2014, havia cerca de 40 núcleos e grupos de estudos sobre feminismo, gênero, e mulheres vinculados a instituições universitárias no Brasil. Mayanne Freitas e Maria Carvalho (2015) fazem, por sua vez, um levantamento de 35 grupos oriundos de IES das regiões Norte e Nordeste do Brasil, dentre os quais 17 núcleos e 12 grupos são da região Nordeste, e outros 04 núcleos e 02 grupos da região Norte.

O primeiro grupo de trabalho a ser criado, no Brasil, foi o Grupo de Trabalho Mulher e Força de Trabalho, na Associação Nacional de Pós-Graduação e Pesquisa em Ciências Sociais (ANPOCS), em 1979, pela socióloga Heleieth Saffioti, e desde 1991, reúnem-se para traçar estratégias conjuntas. Na Pontifícia Universidade Católica do Rio de Janeiro, em 1980, viu-se o nascimento de uma iniciativa da cientista política Fanny Tabak, o GT Mulher e Política. Conforme aponta Elena Schuck (2018, p. 37) “a atuação em separado dos grupos findou em 1989, quando foram unificados no GT Estudos das Relações Sociais de Gênero." O Núcleo de Estudos da Mulher (NEM), da Pontifícia Universidade Católica do Rio de Janeiro, também iniciativa de Fanny Tabak, surge em 1980, seguido, em 1981, do Núcleo de Estudos, Documentação e Informação sobre a Mulher (NEDIM)

Outros mais antigos em suas respectivas regiões são: Núcleo de Estudos Interdisciplinares sobre a Mulher - NEIM (UFBA), criado em 1883; Núcleo Indisciplinar da Mulher e Gênero - NIEM (UFRGS), em 1984; Grupo de Estudos e Pesquisas Eneida de Moraes da Mulher e Relações de Gênero - GEPEM (UFPA), em 1994; Núcleo de Identidades de Gênero e Subjetividades (NIGS) (UFSC), em 1991; Núcleo de Estudos da Mulher e Relações Sociais de Gênero - NEMGE (USP), em 1985; Núcleo de Estudos de Gênero - PAGU (UNICAMP), em 1993; e o Núcleo Interdisciplinar de Pesquisa e Ação em Mulher e Relações de Sexo e Gênero - NIPAM (UFPB), em 1998 (COSTA, SARDENBERG. 2014; SCHUCK, 2018).

Articulações desse tipo existem ainda em associações científicas, como já foi dito. Destacamos a criação da Rede Regional Norte-Nordeste de Estudos e Pesquisas 
sobre a Mulher e Relações de Gênero (REDOR), em 1992, para incentivar a troca da produção científica dos núcleos e grupos das regiões menos favorecidas com recursos e estrutura. Da nossa experiência, podemos citar dois grupos que têm contribuído frutiferamente com as discussões em gênero, sexualidade, feminismos e direito, na Bahia: o Jusfemina - Grupo de Pesquisa e Ação em Gênero, Direito e Políticas para a Igualdade e o Gira - Grupo de Estudos Feministas em Política e Educação.

A tarefa deste trabalho é buscar um olhar de dentro desses grupos e núcleos para expressar suas relações de poder e conflitos internos, bem como sua (falta de) experiência democrática feminista. Isso foi feito através de depoimentos de oito docentes de universidades brasileiras, que tiveram participação em núcleos e grupos de estudos sobre gênero, feminismos e mulheres, sendo que suas identidades serão resguardadas, a pedido.

A seguir apresentamos o marco legal desse assédio, qualificado como moral.

\section{Assédio moral: breves apontamentos}

O assédio moral caracteriza-se pela total ausência de perspectiva ética no tratamento profissional da outra pessoa. Caracteriza-se pela utilização da violência moral. Ela se apresenta nas práticas hierárquicas e/ou autoritárias do cotidiano profissional, causando a degradação da pessoa vítima via transtornos de ordem psíquica, aviltamento à dignidade e identidade, e prejuízos à saúde. Sua prática favorece à "discriminação no trabalho, a manutenção da degradação das relações de trabalho e a exclusão social.” (MINISTÉRIO DO TRABALHO E EMPREGO, 2009, p. 15).

Essa violência traz danos generalizados às envolvidas ${ }^{8}$, com maior impacto na vida e no trabalho das vítimas, que podem se sentir menos eficientes e sofrer queda produtiva, pela desestabilização emocional induzida por sentimentos de medo, incerteza e angústia a qual vem sendo submetida. As mulheres e os homens, estes principalmente em relação ao aspecto da orientação sexual, são os grupos alvos preferenciais juntamente com doentes, acidentadas e pessoas negras. Por se caracterizar como uma violência psicológica, ela atribuiria riscos invisíveis de ordem psicossocial (GONÇALVES, 2006).

Atualmente, não há nenhuma lei federal em vigor sobre o tema, mas em 12 de março de 2019, o Plenário da Câmara dos Deputados votou o Projeto de Lei 4742/01, tipificando o assédio moral como crime no Código Penal. Com pena estipulada em um a dois anos de reclusão e multa, o projeto (agora sob o título de Projeto de lei $n^{\circ} 1521$, de 2019) segue para apreciação e votação no Senado (CÂMARA, 2019). No texto, o crime de assédio moral estará indicado pelo artigo 146-A e descrito como ato de "Ofender reiteradamente a dignidade de alguém causando-lhe dano ou sofrimento físico ou mental, no exercício de emprego, cargo ou função” (BRASIL, 2019).

\footnotetext{
Sobre esse tema, o Jusfemina, com apoio do Gira, organizou, em 2019, uma jornda com o título "Assédio moral no trabalho em universidade: por uma política de prevenção e combate”. Pesquisadores/as, professores/as e servidores/as da Universidade Federal da Bahia participaram como palestrantes, assim como representantes da Pró-Reitoria de Desenvolvimento de Pessoas (PRODEP), da Associação de Servidores Técnico-Administrativos da UFBA (ASSUFBA) e Associação de Professores Universitários do Estado da Bahia (APUB).
} 
Conceitualmente, assédio moral se refere a coações e perseguições, comportamentos agressivos e/ou humilhantes contra a outra pessoa dentro do ambiente de trabalho. Ações que reverberam consequentemente sobre o campo dos direitos humanos e respeito à dignidade da pessoa humana, trazendo para seu cerne uma discussão inseparável da ética ou moral. Deve-se fazer uma distinção conceitual entre assédio moral e conflito. Aquele não pode ser colocado como uma extensão deste por constituir-se numa relação desigual de poder, na qual há uma posição de dominador e dominado definida. Ao contrário do conflito, no qual as envolvidas podem chegar a uma resolução, a partir de uma discussão em posições igualitárias ou sem desníveis acentuados (GONÇALVES, 2006). Também precisamos deixar explícito que não pretendemos aqui estabelecer uma equivalência entre assédio moral e relações autoritárias. Embora dialoguem, essas questões não são sinônimas, pois é em espaços autoritários que o assédio se manifesta, sua expressão depende de um contexto em que o autoritarismo e a ausência de democracia organizam as relações de poder.

O assédio moral, no caso ora em análise, é mais comum do que se vê. Tanto o vertical, de cima para baixo, das chefas em relação a suas subordinadas, como misto, que inclui o assédio entre colegas. A simultaneidade dessas práticas deve-se também a um ambiente permeado por relações autoritárias, uma cultura, forma de organização basilar das relações nesses espaços. A Interlocutora7, ao denunciar o assédio sofrido no Núcleo que trabalha, remete-nos a uma articulação complexa, que ultrapassa o nível da individualidade. Atribui-se a essa prática uma existência herdada, a continuação e atualização de velhos e - porque não - podres poderes:

Eu fui vítima de assédio moral no trabalho. Constante. [...] O que eu vivi foi uma perseguição profissional. Vivo até hoje. E que se tornou... ela passou de uma perseguição deliberada para uma evitação. [...] Assédio moral [...] vem de muito longe. Eu não acho que é de agora. A gente simplesmente entrou numa engrenagem que já era assim. (Interlocutora 7, grifos nossos).

Outro aspecto do assédio moral é a invisibilização, silenciamento, apagamento e exclusão, violências sofridas por ampla maioria de nossas interlocutoras. Nas palavras de uma entrevistada, "elas me silenciam, elas me ignoram, não levam nada em conta". (Interlocutora 8). A falta de reconhecimento da pessoa e seu trabalho, implicando na negação de seu protagonismo, foi outra dimensão destacada por nossas entrevistadas, como relata a Interlocutora 8: "basicamente tudo o que a gente fazia no grupo tinha a ver com difusão científica - era eu que fazia e nunca foi me dado crédito. [...] Eu saí, desse grupo de pesquisa, por conta de não me sentir reconhecida, de me sentir agredida”.

A subutilização e a superutilização, categorias que são levantadas direta ou indiretamente na fala das nossas interlocutoras, também figuram como práticas recorrentes de assédio moral nesses espaços. A Interlocutora 7, faz-nos refletir que em alguns casos a subutilização decorre ou aplica-se concomitante à falta de reconhecimento, 
desconsideração da produção e atuação profissional. Ou seja, como não se valoriza seu trabalho, não se vê motivos para a inclusão da pesquisadora e utilização de suas capacidades e competências para o trabalho coletivo - quando o há. A Interlocutora 3 liga as relações hierárquicas com a subutilização: "não tem interlocução, me sentia solitária, meu conhecimento pouco aproveitado, relações hierárquicas".

Há uma diversificação na prática do assédio moral, que não pode ser tomado como uma relação linear de fácil apreensão, posto que, às vezes, pode apresentar situações que consideraríamos contraditórias, como no caso da Interlocutora 4 que, por sua vez, traz o processo de superutilização como prática de assédio moral, mas também o sentimento de desvalorização:

O processo no Núcleo não é de subutilização. É de superutilização. [...] E quando eu questionava, ou alguém mais questionava esta questão da superutilização, [...] geralmente a resposta era que: "olha, isso é muito legal para você também, você vai negar que é legal para você, que também lhe traz vantagens?” Nunca era o suficiente. Eu não me sentia valorizada naquele espaço, não. Essa é a verdade. Eu me sentia ansiosa de ser valorizada. (Interlocutora 4 , grifos nossos).

A falta de transparência em processos seletivos internos suscita a exclusão como prática de assédio moral. Ao questionar a forma segundo a qual seu Núcleo lidava com a incorporação de docentes ao Programa de Pós-Graduação, a Interlocutora 3 nota "incongruências e incoerências" que seriam decorrentes de uma forma de monopólio, no qual um seleto grupo escolheria segundo seus critérios pessoais e interesses particulares quem deveria entrar. Essa relação de instrumentalização de instância acadêmica

Foi o primeiro momento que eu percebi que existia tratamento diferenciado, que existia predileção, que existia desigualdade entre membros de um mesmo Núcleo. [...] Interditaram colegas que elas não queriam que estivessem lá dentro. (Interlocutora 3).

Todos esses discursos revelam e reiteram que assédio moral tem ocorrido das mais diversas formas, com os mais diversos sujeitos. Mas que se assenta numa cultura autoritária, que tolhe a democracia que deveria ser constitutiva de qualquer espaço de trabalho coletivo, sobretudo aqueles de construção do conhecimento e políticas do bem viver, como o deveriam ser os núcleos feministas.

Traçamos a seguir o componente geracional desse assédio moral. 


\section{Questões geracionais}

Eliane Gonçalves e Joana Pinto (2011, p. 34) destacam que a "outra face igualmente importante do feminismo brasileiro se constrói na academia, muitas vezes de forma híbrida, com ativistas que principiaram nos coletivos informais dos anos 1970 e seguiram carreiras profissionais nas universidades". Ou seja, o espaço acadêmico foi crucial na ampliação e fortalecimento do movimento feminista. Mas nos estimulam a indagar de que maneira suas contribuições desde essa estrutura foram salutares à transmissão intergeracional? Há nos espaços feministas a utilização da geração como um fator de desautorização profissional e/ou desigualdade?

$\mathrm{Na}$ defesa das autoras, a "transmissão geracional" seria facilitada por uma organização horizontal, opção política que foi privilegiada pelo movimento feminista enquanto metodologia. A ausência da horizontalidade na prática e nos grupos feministas, então, prejudicaria essa transmissão e, consequentemente, a formação e construção do conhecimento. A metodologia de horizontalidade de poder e saber e os princípios de igualdade são um estímulo à transmissão geracional, visto que a não hierarquização contribui para uma cultura polifônica, em que todas as vozes, em teoria, seriam ouvidas. No caso de um dos núcleos trazido nos relatos de nossos/as interlocutores/as, essa transmissão, como imposição, foi um insucesso, por seu caráter verticalizado (GONÇALVES; PINTO, 2011).

Como mostra a/o Interlocutora 6 , ao referir-se a um núcleo feminista do qual fez parte, a questão geracional e sua transmissão eram - talvez ainda sejam - pontos transversais nas relações de poder naquele espaço:

Tinha a questão geracional, que eu falei. Eu sei que as mais velhas sempre vão pensar na memória, nos objetivos traçados, nas estratégias realizadas, dar um freio também para as irresponsabilidades das mais jovens, dos mais jovens, mas isso tem que ser com transparência e com cuidado. Transparência no sentido de dizer: essas decisões têm de ser tomadas por tais e tais motivos, não com subterfúgios de silenciamento. Mas existe, como qualquer estrutura humana. (Interlocutor 6).

Apesar da horizontalidade como premissa do movimento feminista, "para algumas jovens feministas o problema que se coloca é de assimetria, de acesso diferenciado a poder, de falta de legitimação de suas falas" (GONÇALVES; PINTO, 2011, p.38). Gerações anteriores do movimento feminista acabam monopolizando o poder e cristalizando as ações políticas, não possibilitando o diálogo e trocas intergeracionais. A preocupação está na transmissão política de uma geração mais velha para outra mais nova. Há, aparentemente, uma perspectiva unilateral nesse processo de transmissão, sem diálogos ou trocas, como demonstra a Interlocutora 8 ao relatar o que sentia ao fazer parte de um grupo feminista chefiado por mulheres mais velhas: 
O sentimento de ser invisibilizada, silenciada, da minha opinião não ser considerada. Eu me sentia [...] uma estagiária, sem direito a voz, sem direito a protagonismo. [...] No início da minha trajetória feminista, sofri bastante com as feministas mais velhas, por esse silenciamento. (Interlocutora 8, grifos nossos).

O problema geracional, como visto, vai muito além da questão da transmissão, mas toca também a dimensão democrática dos espaços feministas: quem pode ou não opinar e como deve opinar? Quando falar e quando calar-se? Ao contrário do que se pode pensar, a questão geracional não diz primeiramente da dimensão gerontológica, a idade física dessas mulheres. Mas refere-se dimensão temporal-simbólica subentendida nessas relações de poder, aquela que se relaciona à chegada temporal num determinado lugar ou atuação num determinado campo. Sendo assim, algumas feministas veem no dispositivo geracional também um mecanismo de destituição e outorgação de poder e palavra, como podemos tirar do relato da Interlocutora 4, quando compartilha sua experiência em núcleo feminista:

As papisas com as últimas palavras, as mais jovens, algumas mais jovens - digamos, não cronologicamente, mas as mais jovens de terem chegado ali - se calando. [...] "Ou você está com a gente ou você está fora”. [...] Acaba se fiando muito no discurso de quem tem a experiência, de quem já está lá no lugar de uma certa antiguidade, de uma certa autoridade construída ao longo do tempo. [...] Nem sempre as informações estão acessíveis de uma maneira muito democrática. (Interlocutora 4).

Unimo-nos às autoras ao reiterarmos a pertinência de reflexões, problematizações e críticas ao movimento feminista, ao campo dos estudos de gênero ao qual pertencemos e às próprias teóricas e/ou militantes feministas a partir do questionamento/ visibilização da dimensão geracional nesses espaços ou seu uso como instrumento de manutenção de relações hierárquicas autoritárias, permeadas por desigualdades de distribuição de prestígio, reconhecimento, e silenciamentos. Este é um tema pouco trabalhado dentro do movimento e que demonstra impasses nas "estratégias de formação contínuas” (Eliane GONÇALVES; Joana PINTO, 2011, p. 27). Cabe-nos, mediante o que foi trazido e consoante às autoras, pautar a necessidade de uma reelaboração analítica que versará sobre as problemáticas da transmissão intergeracional que perpassa o movimento e a democracia nos espaços feministas acadêmicos. 


\section{Público e privado: inversões conceituais na prática feminista}

Como explica Susan Okin (2008, p. 313) "a família se tornou, e vem se mantendo desde então, central à política do feminismo e um foco prioritário da teoria feminista." Desde a década de 1960, as feministas vêm debatendo as relações entre público e doméstico, para usar os termos de Okin (2008). No entanto, ela reforça que “a maioria das feministas do século XIX - e do início do XX - não questionou ou desafiou o papel especial da mulher no interior da família." (Susan OKIN, 2008, p. 312). E, além disso, como mostra, as discussões em torno dessa dicotomia dividiam feministas: havia aquelas que defendiam a total destruição do âmbito doméstico, e havia aquelas que, ao pautar a maior expressão na esfera pública, também acentuavam um caráter inato e natural de sua relação com o espaço do lar.

Resultado desses debates e esforços de feministas radicais e socialistas durante a década de 1960, momento que ficou conhecido como a segunda onda do movimento feminista, foi o slogan “o pessoal é político". Como o próprio mote explicita, politizou-se as relações consideradas de foro íntimo, posto que se há ali relações desiguais de poder mediadas por discursos externos, elas não poderiam continuar circunscritas a quatro paredes.

Este momento do feminismo foi revolucionário na medida em que provocou reações coletivas de mulheres para transformação de sua realidade, principalmente por embaçar as barreiras entre o público e o privado, fomentando debates sobre a imisção de uma dimensão na outra e reforçando não somente o debate sobre a invisibilidade da mulher na esfera pública, como questionando as relações domésticas. Nesse contexto, os grupos de conscientização foram os catalizadores das dores das mulheres que ali se encontravam para compartilhar suas experiências, possibilitando a compreensão de seu estado de exploração e subordinação como relações de poder desiguais que incidiam coletivamente sobre suas vidas (Cecília SARDENBERG, 2018).

Se o "pessoal é político" foi uma tentativa de politização das relações domésticas e denúncia da opressão estrutural sofrida por mulheres, aliada a uma demanda de maior participação pública e questionamento do âmbito privado; devemos considerá-lo como um investimento também democrático. Mas por que trazer essa discussão aqui? Onde ela toca o tema deste artigo? Nossas interlocutoras trouxeram em seus relatos o que nos pareceu uma inadequação prática do sentido de "o pessoal é político" na forma como algumas feministas têm organizado as relações em núcleos de pesquisa em gênero em universidades brasileiras. Isso nos levou a perguntar como as feministas interpretam esse lema? Quais as possíveis transformações que ele pode ter sofrido? Pode ele ser mal interpretado na prática feminista?

Observamos, então, o que chamaremos de familismo, entendido aqui no seu sentido patrimonialista (AGUIAR, 2000), premente na forma de organização de alguns desses espaços que descaracteriza e vai contra o lema feminista da década de 1960. Ademais, constitui-se numa prática que atenta igualmente contra qualquer valor democrático, posto que se entende o pertencimento, o reconhecimento e a 
palavra mediados por questões de foro íntimo, afetivas, num espaço cujas as relações deveriam ser prioritariamente profissionais e políticas, onde as preferências afetivas interpessoais, de comadrio, amizade ou parentesco, não deveriam imperar como marco determinante do desenrolar e constituição das relações. A retratação do Núcleo ao qual era fiiliada, feita pela a Interlocutora 6, denota que

as coisas sempre foram assim mais familiar. Meio o que elas contam, é que era um ambiente de amizade, [...] que era um ambiente tipo barzinho, da casa, do chá, do almoço... que as decisões, que as coisas eram tomadas no sentido de... [informalidade]. Mas uma informalidade com um propósito, né? Acho que o lema do feminismo, "o pessoal é político", tava amarrado ali nessas coisas, que também havia solidariedade nesse sentido, das pessoas que são mais próximas estarem tomando decisões. (Interlocutora 6, grifos nossos).

Não há que se negar a importância dos afetos na política e no trabalho, mas quando falamos de afetos na política, dizemos de desejos e todas as emoções suscitadas por aqueles e sua necessária interpretação para o decorrer das relações políticas de maneiras democráticas e horizontais. Diferentemente da imposição de relações familistas com vistas à manutenção do poder e o controle por poucas, estabelecendo fortes hierarquias desiguais dentro de espaços feministas. Sobretudo em espaços universitários de produção de conhecimento e políticas. Atribuir a essa prática comentada pela Interlocutora 6 uma relação com a ideia de "o pessoal é político" revela uma inversão conceitual no plano prático e das ideias tanto das feministas desse núcleo quanto da própria interlocutora.

O familismo ainda se faz mais visível quando a Interlocutora 6 menciona como a abertura de um concurso público para aquele Núcleo gerava um certo medo de que as decisões deixassem de ser tomadas no foro das relações pessoais e passassem, como o deveriam ser desde o princípio, serem tomadas objetivamente, levando em consideração o espaço e a sua finalidade política, tomadas de forma democrática, pelo diálogo, convencimento e conflito entre pares com opiniões e pesos equivalentes. Trata-se, logo, de uma relação sobre ausência de democracia e transparência que fica tanto mais evidente no seguinte relato:

Havia uma preocupação nesse sentido né? De que as relações, o concurso seria público, e que as relações deixariam de ser tão familiares assim, o que poderia haver sim interesses divergentes e contraditórios e os interesses da própria organização. Como ela tava crescendo, quais eram os projetos vinculados, né? Tinha uma preocupação quanto a isso. Quais seriam os rumos que se dariam depois desse concurso aberto? (Interlocutora 6, grifos nossos). 
O patrimonialismo expresso nas relações feministas em núcleos universitários não só denota um desentendimento do significado do cargo público e do ambiente universitário, como um desinvestimento democrático: no sentido de impossibilitar a condução horizontal das relações nesses espaços, uma vez que parte de um modelo doméstico de organização, na qual, infelizmente, vemos a relação como o desempenho de duas funções maternas de qualidades antagônicas, como pontuou a Interlocutora 5 comentando a forma como uma feminista mais velha do seu núcleo lidava com a denúncia de assédio moral que a primeira vinha sofrendo:

aquela coisa lógica da [...] mãe, né, ela não operava com a gente de igual pra igual. Ela operava da lógica da mãe, ela achava que era a mãe de todo mundo, né. E a mãe boa e a mãe má, também, né. A mãe madrasta. Então era uma lógica, assim... "vou falar com a [...], não pode, isso não é possível”. Tipo assim: "vou falar com tua irmã mais velha, vou colocar ela de castigo". (Interlocutora 5, grifos nossos).

Ademais, os problemas não eram resolvidos institucionalmente como o deveriam, mas pela lógica "roupa suja se lava em casa". O interesse da família, que, na verdade, tratava-se do domínio do interesse de algumas, assinalava a política interior e exterior a ser trabalhada pelo coletivo. Qualquer ato "contrariando o decreto da grande mãe" era matéria de fortes discussões e reprimendas. Há uma ideia de organização e superioridade do "interesse coletivo" que passava por cima da autonomia de qualquer pessoa que lhe apresentasse alguma ameaça. Quando uma questão de interesse público não pode ser discutida na esfera pública, porque contraria a "grande mãe", vemos aí a imposição do modelo doméstico familiar. O que se extrai então desse contexto é a reprodução da lógica liberal de organização das relações públicas e privadas, tão criticada pelo movimento feminista. Mas nessa configuração, a relação de desigualdade do foro íntimo estrutura-se no âmago de instituições públicas. A interlocutora 7 utiliza a figura da "mãe" para traçar uma crítica ao Núcleo em que atua:

O Núcleo não passa de um clube de mães. E aquele prédio é a sede do clube de mães e de esposas. Esposas de gente poderosa. É isso. Ali é um prédio de esposas e mães, um clube de esposas e mães. Só que cresceu, teve concurso: [...] não é mais um lugar de comadre. (Interlocutora 7).

Essa questão doméstica e patrimonialista demonstra as relações de poder no seio dessas instâncias feministas e acadêmicas, mas também uma contradição práticoteórica, envolvendo as relações de poder e a democracia. 


\section{Relações de poder e democracia}

A teoria e o movimento feministas vêm passando por inúmeras transformações desde seu surgimento, seja a partir da reivindicação de mulheres negras cobrando a racialização do gênero, seja de mulheres lésbicas cobrando a sexualização do gênero, seja de mulheres trans denunciando o cissexismo do movimento e teoria feminista, assim como mulheres indígenas, autóctones e africanas que se revoltam contra uma narrativa etnocêntrica e nortecentrada sobre a experiências das mulheres. $O$ que acontece aqui são relações de poder no interior de um movimento e teoria políticas, disputas e embates inerentes às construções políticas e epistemológicas (GALINDO, 2016; MIÑOSO, 2014; COLLINS; 2019; CURIEL, 2007; FALQUET, 2012; HOOKS, 2019; OYĚWÙMÍ, 2017). Disputas de narrativas contra a imposição de uma narrativa homogênea sobre as realidades múltiplas das mulheres, que são atravessadas por categorias como raça, classe, sexualidade, deficiência, religiosidade, território e identidade de gênero etc. (CRENSHAW, 2002, 2012).

No entanto, as relações de autoritarismo e assédio moral observadas em espaços feministas universitários demonstram que, ao contrário do que pressupõe a Antropologia Feminista (BONNETTI, 2009), o poder enquanto elemento constitutivo das relações, objeto de tantas análises e constitutivo do conceito de gênero, parece passar despercebido pelas feministas desses núcleos. A ausência de uma discussão sobre a assimetria de poder nesses espaços e utilização da hierarquia parece ser um meio para a manutenção de velhas estruturas, consideradas heranças de uma tradição patriarcal da política (PATEMAN, 1993; COSTA, 1998, AGUIAR, 2000). Na visão da/o interlocutora 5:

Há uma interdição de falar sobre poder entre ou intra feministas. [...] Tem um tabu em falar do poder entre nós, feministas... como se a gente fosse imune a ele, ou como se a gente soubesse lidar muito bem com ele. [...] Mas eu não acho que a responsabilidade seja exclusiva delas. (Interlocutora 5).

Muito das expressões do autoritarismo remetem a uma cultura maior que, embora não implique na desresponsabilização das autoras, também não pode ser desconsiderada de qualquer análise. Nesse sentido, a prática autoritária se coaduna com aspectos culturais locais e globais e outros sistemas de opressão (CRENSHAW, 2002, 2012) - como a homofobia ${ }^{9}$, o racismo, o coronelismo ${ }^{10}$, em suma, eixos de

\footnotetext{
9 Numa decisão histórica, em 13 de junho de 2019, o Supremo Tribunal Federal determina que a discriminação por orientação sexual e identidade de gênero seja considerada crime, punível segundo a Lei Anti-Racismo, nº. 7716/89. Ver BARIFOUSE, 2019.

${ }^{10}$ Sobre o termo "coronelismo" ver NUNES LEAL, Victor, 1977, onde ele discorre sobre uma aliança entre "coronéis" locais e o poder público
} 
produção de violência ${ }^{11}$ - vindas de colegas feministas no ambiente unversitário, conforme a fala, abaixo, da interlocutora 7 :

[a] burocracia é uma forma de manutenção dessa cultura autoritária. [...] elas são super autoritárias, [...] antifeministas, [...] contraproducentes, [...] heterossexistas, [...] homofóbicas e [...] racistas. Elas são violentas, são pessoas violentas. (Interlocutora 7, grifos nossos).

Quanto à centralização do poder e das decisões, ela ocorre, principalmente, com fundadoras e personalidades mais autoritárias. A hierarquia formal fortalece a hierarquia informal, onde as feministas autoritárias se comprazem em serem chefas em detrimento de processos mais colaborativos e horizontais. Com isso, comprometem a democracia interna nos espaços acadêmicos feministas

Eu não percebia que existia ali umas hierarquias entre as poucas professoras que compunham aquele [...] elas estão em todos os lugares sendo chefas... [...] São espaços capitaneados por figuras que se repetem, se perpetuam nos cargos, no poder, no comando. [...] porque o autoritarismo ele nem sempre aparece de maneira ostensiva. (Interlocutora 3, grifos nossos).

A Interlocutora 3 chama atenção para a dimensão da política e filiação partidária como preponderante no delinear das relações dentro do seu Núcleo. A intolerância política assume seu aspecto sutil, não mais tão polarizado quanto sua expressão pública nos embates direita vs. esquerda, conservadores vs. progressistas. Crítica de esquerda só contra a direita, parece que para as incongruências políticas de seus partidos ou da própria esquerda deve-se passar panos quentes, "porque as feministas da nossa Universidade quando analisam as políticas públicas, elogiam os governos de esquerda por tudo que eles façam" (Interlocutora 3).

De forma muito mais insidiosa, essa intolerância ou aversão às críticas feitas à esquerda e seus partidos, mesmo feitas por quem também se situa no espectro político de esquerda se expressa na exclusão, silenciamento, mandos e desmandos autoritários. Algumas vezes se expressa mais diretamente em ataques verbais do tipo "temos uma coxinha entre nós”. Com o autoritarismo partidário, cerceia-se também a liberdade de crítica, a liberdade política e a autonomia. Tenta-se impor um pensamento e política universal, exigindo senão enquadramento das Outras, silenciamento. A exemplo disso as Interlocutoras 3 e 5 informam:

\footnotetext{
${ }^{11}$ Violência é aqui entendido como todo ato de coerção, opressão, intimidação e tirania e se manifesta causando danos físicos, morais, patrimoniais, sexuais, psicológicos e emocionais. A violência se apresenta no local de trabalho, nos espaços de poder, dentro da família e no âmbito doméstico (Cristina BUARQUE et al, 2011). Há também a definição de Marilena Chauí (2012, p. 157), para quem a "violência é toda prática e toda ideia que reduza o sujeito à condição de coisa que viole interior e exteriormente o ser de alguém”.
} 
Era mais tipo...um conjunto de mulheres que giravam no entorno das fundadoras. E as fundadoras, supostamente moralmente superiores, intelectualmente superiores, politicamente superiores. [...] Elas naturalizam o autoritarismo quando se beneficiam. [...] $\mathrm{O}$ Núcleo de pesquisa nem discute eleição ${ }^{12}$, não discute nada. Porque já está dado que todo mundo tem que ser petista, tem que ser comunista, do partido. [E se não for] [...] você é demonizada: você é coxinha, você tá do lado da direita. Então todo esse discurso que de algum modo é pra evitar que os sujeitos tenham coragem de pensar com a própria cabeça, vai afetar a nossa psiquê, vai ter desdobramentos no nosso corpo. (Interlocutora 3).

A experiência do Núcleo era uma experiência de absorção total da sua vida, lhe apagar como sujeito. Você tinha que se apagar como sujeito e tinha que seguir aquela lógica, aquela regra ali. Não seguindo, resistindo em manter sua autonomia enquanto sujeito, você continua sendo uma pessoa proscrita, não bem-vinda. (Interlocutora 5, grifos nossos).

A existência de processo eleitoral não deve ser tomada como suficiente se ele aparece com inconsistência. Destacamos que, num dos núcleos e grupos, a eleição interna se constitui, segundo seu regimento ${ }^{13}$, a partir da reunião com a presença da maioria simples dos votos, tendo o/a Presidente/a do Conselho dois votos, um enquanto maioria simples e outro de desempate. Nesse sentido, a fala da Interlocutora 3 exige uma reflexão e reavaliação dos termos eleitorais, posto que uma atribuição desigual de poder de decisão muitas vezes atende valores particulares e vão contra uma gestão de fato democrática. Ressalte-se ainda que a interlocutora refere-se, ainda, a eleições partidárias, tanto municipais, como estaduais e federais

É importante reafirmamos, mais uma vez, que não se trata aqui de conflito, não no sentido que defendemos a partir de Chantal Mouffe (2005); pelo contrário, o que se tem aqui é total supressão do conflito tanto pela negação das singularidades quanto pelas investidas autoritárias que eliminam o contraditório, a possibilidade de diferenciação e oposição, o livre exercício do pensamento e da crítica, como nos mostram as Interlocutoras 3 e 5. Cabe-nos a difícil tarefa de trazer essas situações para cena pública, não como um reflexo geral das relações feministas na Academia, mas como recortes de uma realidade que não pode ficar escamoteada sobre os ideais generalistas do movimento feministas, uma vez que não há homogeneidade nem de

\footnotetext{
${ }^{12}$ Marilena Chauí (2012) comenta o significado de eleições. Segundo ela, "muito mais do que a mera rotatividade de governos ou alternância no poder, elas simbolizam o essencial da democracia, ou seja, que o poder não se identifica com os ocupantes do governo, não lhes pertence, mas é sempre um lugar vazio que, periodicamente, os cidadãos preenchem com representantes, podendo revogar seus mandatos se não cumprirem o que foi delegado para representar".

13 Este material não será listado nas referências, posto que o compromisso ético de salvaguardar as identidades das nossas informantes nos impede que a exposição desses dados comprometa seu anonimato.
} 
práticas nem de discursos. Diante disso, essas relações hostis são reflexos da ausência de democracia interna nesses grupos e núcleos e reforçam a assimetria de vocalização em espaços feminista, atentando para as diferença intra-feministas (SARMENTO, 2014), que tocam questões político-partidárias e intolerância política. Mas também se manifesta em preconceitos e monopólios.Por fim, apresentamos as propostas de melhoria das relações em instâncias feministas no interior de universidades.

\section{Considerações finais}

Este trabalho discute a (falta de) democracia em espaços feministas de universidades brasileiras e questiona até que ponto essa realidade, descrita neste artigo, é vivenciada em outras instituições e se o feminismo autoritário está presente nos próprios movimentos feministas e de mulheres, como há evidências. Nesse sentido, constatamos que há muito trabalho ainda a ser feito para transformação dessa realidade, este artigo nem de longe exaure a questão, mas propõe iniciar e visibilizar a problemática, por isso "Considerações Iniciais".

De modo a oferecer alternativas a esse cenário, e tomando suas experiências como bases para o conhecimento da realidade e sua reflexão, pois os Saberes são corporificados (HARAWAY, 2009), nossas interlocutoras foram estimuladas a oferecerem sugestões que contribuam para essa transição de um autoritarismo para relações mais horizontais e dentro da ética feminista.

Observamos que suas proposições podem ser classificadas em gerais, de caráter mais amplas, e específicas, voltadas para solucionar questões determinadas. As proposições gerais envolvem desde a mudança de mentalidade e o cuidado com os pares, a mudança de cultura política, o compromisso com a democracia feminista, a necessidade de afeto, além de transbordar, a partir das instâncias feministas, para as universidades.

Nossas interlocutoras defendem a problematização e nomeação dessas relações como violências como o primeiro passo para um enfrentamento eficaz e honesto do feminismo autoritário e dos abusos que o acompanham. E as feministas, ao rejeitarem o protagonismo no uso do autoritarismo, devem assumir a dianteira na produção de reflexões e conhecimentos sobre essas experiências autoritárias no interior do movimento. Esse deslocamento pressupõe a reafirmação do compromisso com a democracia feminista, numa perspectiva horizontal, que considere a importância do conflito como uma fonte de produção criativa, como sugerem nossas interlocutoras.

Acredito que é a questão da mentalidade. Da mentalidade e não ter medo de se abrir para o questionamento e para rever suas próprias contradições. [...] Se eu posso sugerir às acadêmicas é ler Seyla Benhabib. [...] Ela fala de um eu concreto e de um eu abstrato. Elas precisavam ler de novo, mas pensando no eu abstrato, do cuidado com os seus próprios pares. (Interlocutora 6, grifos nossos). 
Para democratizar as relações de poder, eu acho que... [...] há necessidade de transformação da cultura política e de atividades [...] educativas, informativas, que façam as lideranças desses grupos e núcleos feministas perceberem a sua responsabilidade naquelas que estão hierarquicamente abaixo delas. [...] Então acho de pouquinho em pouquinho, mas com atividades de reflexão e de educação, para ver se a gente consegue transformar um pouco a cultura. (Interlocutora 8, grifos nossos).

Eu acho que a primeira questão é problematizar, [...] e a gente vem fazendo isso nesses enfrentamentos. Colocar isso como uma questão, um problema, como uma violência, nomear isso de uma maneira correta: são violências. São relações de poder autoritárias e desiguais, assimétricas que levam a relações de adoecimento e que eu diria mais, parafraseando as teorias feministas nas relações domésticas e familiares, são relações abusivas. (Interlocutora 3 grifos nossos).

Há necessidade de afeto entre nós [...]. É possível divergir, é possível questionar, sem precisar odiar e ser odiada. Eu imagino que evidenciar esse problema, refletir teoricamente sobre ele, pensar numa perspectiva de que a gente pode exercer práticas que futuramente podem ser consideradas boas práticas. (Interlocutora 3, grifos nossos).

A gente tem uma riqueza, grandes possibilidades em todos os sentidos. Então eu espero que comece pelas próprias instâncias de mulheres dentro da academia, mas que provavelmente vai servir também para outros grupos de mulheres, institucionais, inclusive, para se perceberem mais e, se quiserem, adotar outra postura. Mas só o fato de ter uma maior consciência, acho que já é importante. (Interlocutora 2, grifos nossos).

Quanto às propostas específicas, elas mencionam a construção de processos mais colaborativos, grupais, a existência de mais equipes, ocupação de prédio público privatizado por feministas autoritárias, mudança administrativa das universidades, prevendo uma instância de acolhimento para vítimas de assédio moral.

Eu acho que ali nós deveríamos ter mais equipes. Tinha que ter um grupo de pesquisa sobre a violência contra a mulher. Tinha que ter um grupo de pesquisa sobre movimento feminista. Ocupar aquele espaço, aquele espaço tinha que voltar a ser público. 
Então para mudar, nós temos que mudar a cultura institucional ali dentro. (Interlocutora 7).

Então assim: eu acho que nós temos que cuidar da nossa saúde, cuidar da nossa vida, lutar pelos nossos direitos, somar com outros grupos. (Interlocutora 3).

Eu acho que em relação a núcleo ou grupo de universidade, a mudança não precisa ser somente cultural, pode ser uma $m u$ dança administrativa, né? Então eu acho que quando essas questões de assédio moral ocorrem em espaços da universidade, acho que medidas administrativas que lancem luz a esses problemas e que busquem formas [...] de reparação ou de sanção seriam necessários. Seriam necessários sim. Seria interessante que a gente tivesse para quem recorrer para não ter que abrir mão das nossas vagas na pós-graduação e dos nossos postos de pesquisas, das nossas bolsas, que é o que geralmente acontece: você sofre algum tipo de assédio, você desiste do seu lugar. Então acho que ferramentas administrativas de apuração, e conciliação e reparação desses casos nas universidades seriam necessárias. E aí isso funcionaria para quê? Funcionaria para barrar a superexploração, sobrecarga, exclusão. (Interlocutora 8, grifos nossos).

Os depoimentos são contundentes quanto ao sofrimento vivido por essas pessoas. Será que há uma disposição dos núcleos e grupos de reconhecer essas dores e críticas, e colocar em prática algumas de suas proposições? Até que ponto essas propostas podem ser levadas para outras universidades, instituições, movimentos feministas e de mulheres e outros em geral? 


\section{Referências}

ADORNO, Theodor. Estudos sobre a personalidade autoritária. São Paulo: Editora UNESP, 1950.

AGUIAR, Neuma. Patriarcado, sociedade e patrimonialismo. Sociedade e Estado, Brasília, v. 15, n. 2, p. 303-330, dez. 2000. Disponível em: http://www.scielo.br/scielo. php?script=sci_arttext\&pid=S0102-69922000000200006\&lng=en\&nrm=iso. Acesso em: 16 out. 2020 .

ALVAREZ, Sonia et al. Encontrando os feminismos latino-americanos e caribenhos. Revista Estudos Feministas, Florianópolis, v. 11, n. 2, p. 541-575, jul./dez. 2003.

ÁVILA, Maria Betânia. Radicalização do Feminismo, radicalização da Democracia. Cadernos de Crítica Feminista, Recife, n. 0, ano 1, p. 1-3, 2007.

BANDEIRA, Lourdes Maria; OLIVEIRA, Eleonora Menicucci de. Trajetória da Produção Acadêmica sobre as Relações de Gênero nas Ciências Sociais. In: GT 11 - A Transversalidade no Gênero nas Ciências Sociais. XIX Encontro Anual da ANPOCS. Caxambu, out. 1990.

BARIFOUSE, Rafael. STF aprova a criminalização da homofobia. BBC News, São Paulo, 13 jun. 2019. Disponível em: https://www.bbc.com/portuguese/brasil-47206924. Acesso em: 25 ago. 2020.

BIROLI, Flávia. Autonomia e desigualdades de gênero: contribuições feministas para a crítica democrática. Vinhedo: Editora Horizonte, 2013.

BONETTI, Alinne. Etnografia, Gênero e Poder: Antropologia Feminista em ação. Mediações, Londrina, n. 2, v. 14, p.105-122, 2009.

BRASIL. Projeto de lei $n^{\circ} 1521$, de 2019. Altera o Decreto-Lei n 2.848 , de 7 de dezembro de 1940 (Código Penal), para tipificar o assédio moral. Brasília, DF: Senado Federal. Disponível em: https://legis.senado.leg.br/sdleg-getter/documento?dm=7928042\&ts= 1594032970535\&disposition=inline. Acesso em: 23 jul. 2020.

BRITO, Angela Ernestina Cardoso de. A balança de EFA: uma análise quantitativa de raça e gênero sobre a inserção de negros e negras no magistério superior da UFBA (2016-2017). Gênero, Niterói, v. 18, n. 1, p. 6-25, 2. sem. 2017. Disponível em: <http:// www.revistagenero.uff.br/index.php/revistagenero/article/view/1030/470>. Acesso em: 18 maio 2019. 
BUARQUE, Cristina et al. Das lutas à lei: uma contribuição das mulheres à erradicação da violência. Recife: A Secretaria, 2011.

BUENO, Sinésio Ferraz. Theodor Adorno e Hanna Arendt: confluência no campo da filosofia da educação. Educar em Revista, Curitiba, n. 49, jul./set, 2013.

CÂMARA aprova punição para assédio moral no trabalho. Agência Câmara de Notícias, 12 mar. 2019. Disponível em: https://www.camara.leg.br/noticias/553265camara-aprova-punicao-para-assedio-moral-no-trabalho/. Acesso em: 23 jul. 2020.

CHAUÍ, Marilena. Democracia e sociedade autoritária. Comunicação e Informação, Goiânia, v. 15, n. 2, p. 149-161, jul./dez. 2012.

COLLINS, Patricia Hill. Pensamento feminista negro. São Paulo: Boitempo, 2019.

COSTA, Ana Alice Alcântara. As donas no poder: mulher e política na Bahia. Salvador: NEIM/UFBA: Assembleia Legislativa da Bahia,1998. Disponível em: http://www. neim.ufba.br/site/arquivos/file/donasnopoder.pdf. Acesso em: 16 out. 2020.

COSTA, Ana Alice Alcântara; SARDENBERG, Cecília. Teoria e Práxis Feminista na Academia: os núcleos de estudos sobre a mulher nas universidades brasileiras. Revista Feminismos, Salvador, n. 2, v. 2, maio/ago. 2014.

CRENSHAW, Kimberlé. Documento para o encontro de especialistas em aspectos da discriminação racial relativos ao gênero. Estudos Feministas, Florianópolis, v. 10, n. 1, p. 171-188, 2002.

CRENSHAW, Kimberlé. A intersecionalidade na discriminação de raça e gênero. Ação Educativa, p. 7-16, 2012.

CURIEL, Ochy. Critique postcoloniale et pratiques politiques du féminisme antiraciste. Mouvements: des idées et des luttes, Paris, v. 51, n. 3, p.119-129, set. 2007. Semestral. Disponível em: https://www.cairn.info/revue-mouvements-2007-3-page-119.htm. Acesso em: 28 nov. 2017.

FALQUET, Jules. Romper o tabu da heterossexualidade: contribuições da lesbianidade como movimento social e teoria política. Cadernos de Crítica Feminista, Recife, v. 1, n. 5, p. 8-31, dez. 2012. Disponível em: https://julesfalquet.files.wordpress.com/2010/05/ art-port-romper-o-tabu-da-heterosexualidade.pdf. Acesso em: 12 maio 2019.

FOUCAULT, Michel. História da Sexualidade: a vontade de saber. 7. ed. Rio de Janeiro: Graal, 1985. 
FOUCAULT, Michel. Microfísica do poder. 14. ed. Rio de Janeiro: Graal, 2014.

FREITAS, Mayanne Júlia Tomaz; CARVALHO, Maria Eulina Pessoa de. Trajetória dos núcleos de estudos da mulher e relações de gênero integrantes da REDOR. Espaço do Currículo, João Pessoa, v. 8, n. 2, p. 270-279, maio/ago. 2015. Disponível em: https:// periodicos.ufpb.br/index.php/rec/article/view/rec.2015.v8n2.270279/14122. Acesso em: 11 ago. 2020.

GALINDO, Maria. "A homogeneidade do feminismo nos entedia; é preciso criar alianças insólitas”. SUR 24: Revista Internacional de Direitos Humanos, São Paulo v. 13, n. 24, p. 225-235, dez. 2016. Disponível em: https://sur.conectas.org/homogeneidadedo-feminismo-nos-entedia-e-preciso-criar-aliancas-insolitas/. Acesso em: 06 ago. 2020.

GONÇALVES, Christiane; ROCHA, Marcos. Feminismos descoloniais e outros escritos feministas. Fortaleza: Expressão Gráfica e Editora, 2019.

GONÇALVES, Eliane; PINTO, Joana Plaza. "Reflexões e problemas da "transmissão" intergeracional no feminismo brasileiro”. Cadernos Pagu, v. 36, p. 25-46, jan./jun. 2011.

GONÇALVES, Rosemary Cavalcante. O assédio moral no Ceará: naturalização dos atos injustos no trabalho. Orientadora: Regina Heloisa Maciel. 2006. 109 f. Dissertação (Mestrado) - Curso de Psicologia, Centro de Ciências Humanas, Universidade de Fortaleza, Fortaleza, 2006.

HARAWAY, Donna. Saberes localizados: a questão da ciência para o feminismo e o privilégio da perspectiva parcial. Cadernos Pagu, Campinas, n. 5, p. 7-41, jan. 2009.

HARDING, Sandra. Gênero, Democracia e Filosofia da Ciência. RECIIS - Revista eletrônica de Comunicação, Informação e Saúde, Rio de Janeiro, v.1, n.1, p. 163-168, 1. sem. 2007.

HOOKS, bell. E eu não sou uma mulher? Mulheres negras e feminismo. 1. ed. São Paulo: Rosa dos Tempos, 2019.

LEAL, Victor Nunes. Coronelismo, enxada e voto. Rio de Janeiro: Forense, 1977.

MELLO, Anahi, FERNANDES, Felipe; GROSSI, Miriam. Entre pesquisar e militar: engajamento político e construção da teoria feminista no Brasil. Revista Ártemis, Florianópolis, v. 15, n. 1, jan./jul. 2013.

MINISTÉRIO DO TRABALHO E EMPREGO. Assédio moral e sexual no trabalho. Brasília: Ministério do Trabalho e Emprego, Assessoria de Comunicação Social, 2009, 24 p. 
MIÑOSO, Yuderkys Espinosa. Una crítica descolonial a la epistemología feminista crítica. El Cotidiano, México, v. 184, p. 7-12, mar./abr. 2014. Disponível em: http:// www.redalyc.org/articulo.oa?id=32530724004. Acesso em: 18 maio 2019.

MOHANTY, Chandra. Under Western Eyes: Feminist Scholarship and Colonial Discourse. Feminist Review, n. 30, p. 61-88, 1988.

MOUFFE, Chantal. Por um modelo agonístico de democracia. Revista de Sociologia e Política, Curitiba, n. 25, p. 11-23, nov. 2005. Disponível em: https://revistas.ufpr.br/ rsp/article/view/7071. Acesso em: 2 maio 2020.

MYARES, Alicia. Democracia Feminista. Valencia: Universitat de Valencia, 2003.

OYĚWÙMÍ, Oyèronké. La invención de las mujeres. Una perspectiva africana sobre los discursos occidentales del género. Bogotá: Editorial en la frontera, 2017.

PATEMAN, Carole. O contrato sexual. Tradução de Marta Avancini. Rio de Janeiro: Paz e Terra, 1993.

PEDRO, Joana; ZANDONÁ, Jair (org.). Feminismos e Democracia. 1. ed. Belo Horizonte: Fino Traço, 2019.

SANCHEZ, Beatriz Rodrigues. Teorias Feministas da Democracia: embates entre Chantal Mouffe e Seyla Benhabib. In: Seminário Internacional Fazendo Gênero 11 \& 13th Women's Worlds Congress, 11/ 13, 2017, Florianópolis. Anais [...]. Florianópolis: [S. n.], 2017, p. 1-15.

SARDENBERG, Cecília Maria Bacellar. O pessoal é político: conscientização feminista e empoderamento de mulheres. Inclusão Social, v. 11, n. 2, p. 15-29, 13 ago. 2018.

SARMENTO, Raysa. Feminismo e deliberação: aproximações possíveis. Brasília: DCP/ UFMG, 2014.

SILVA, Salete Maria da. A carta que elas escreveram: a participação das mulheres no processo de elaboração da Constituição Federal de 1988. Orientadora: Ana Alice Alcântara Costa. 2011. 321 f. Tese (Doutorado em Estudos Interdisciplinares sobre Mulheres, Gênero e Feminismo) - Faculdade de Filosofia e Ciências Humanas, Universidade Federal da Bahia, Salvador, 2011. Disponível em: https://repositorio. ufba.br/ri/handle/ri/7298. Acesso em: 16 out. 2020. 
SILVA, Salete Maria da. Eleições 2018: o lugar das mulheres nas chapas majoritárias. Cadernos de Gênero e Diversidade, Salvador, v. 4, n. 4, p. 91-122, jan./mar. 2018a. Disponível em: https://portalseer.ufba.br/index.php/cadgendiv/article/view/29349. Acesso em: 16 out. 2020.

SILVA, Salete Maria da. Feminismo jurídico: uma introdução. Cadernos de Gênero e Diversidade, Salvador, v. 4, n. 1, p. 83-102, jan./mar. 2018b. Disponível em: https:// portalseer.ufba.br/index.php/cadgendiv/article/view/25806. Acesso em: 16 out. 2020.

SILVA, Salete Maria da. Feminismo jurídico: um campo de reflexão e ação em prol do empoderamento jurídico das mulheres. Gênero \& Direito, João Pessoa, v. 8, n. 3, p. 127-150, 30 ago. 2019. Disponível em: https://periodicos.ufpb.br/ojs2/index.php/ged/ article/view/46598/27611. Acesso em: 15 out. 2020.

TORRE, Bruna Della. Com quantos paus se faz uma canoa? Notas sobre a personalidade autoritária. Miolo Revista de Crítica Marxista, n. 50, p. 103-109, 2020.

TORRES, Igor Leonardo de Santana; FERNANDES, Felipe Bruno Martins. Se sofrer LGBTfobia na universidade, denuncie! O Queer Punitivista no contexto de precarização do trabalho. Revista Diversidade e Educação, Rio Grande, v. 5, n. 2, p. 4059, jul./dez. 2017. Disponível em: https://periodicos.furg.br/divedu/article/view/7526. Acesso em: 18 maio 2019.

VERSIANI, Daniela Beccaccia. Autoetnografias: conceitos alternativos em construção. Rio de Janeiro: 7Letras, 2005.

WRIGHT, Sonia Jay. Estratégias de inclusão das mulheres na política institucional: a opinião parlamentar estadual do Nordeste. Curitiba: Instituto Memória, 2016. 